\title{
Fronteiras da Urbanidade Sanitária: sobre o controle da malária
}

\section{Frontiers of Sanitary Urbanity: on malária control}

\section{István van Deursen Varga}

Médico, Doutor (pós-doutorado) em Saúde Pública pela Faculdade de Saúde Pública da Universidade de São Paulo, Professor Adjunto do Departamento de Sociologia e Antropologia da Universidade Federal do Maranhão; Coordenador do Mestrado em Saúde e Ambiente da Universidade Federal do Maranhão.

E-mail: ivargaœuol.com.br

\section{Resumo}

Propomos aqui uma discussão sobre a população rural como objeto de políticas e práticas no campo da Saúde Pública. Interessa-nos identificar quando, de que modo e em que contextos econômicos, políticos e ideológicos ela foi ou vem sendo contemplada com serviços e/ou ações específicas de saúde por parte de instituições públicas. Para isso, enfocamos as políticas de combate à malária, reconhecida, ainda em nossos dias, como a endemia de maior impacto sobre a população rural da Amazônia. Trata-se, portanto, de uma discussão sobre a trajetória das políticas de controle de endemias no Brasil (no contexto da trajetória das políticas de saúde), em especial sobre as instituições responsáveis por sua execução, ilustrada com dados empíricos e trechos de entrevistas que colhemos em trabalhos de campo no Maranhão - o estado com a maior porcentagem de população rural do Brasil. Concluímos com um estudo de caso sobre dados e tendências atuais da malária no estado, e com alguns comentários sobre os atuais desafios para seu controle.

Palavras-chave: População rural; Saúde Pública; Malária; Maranhão. 


\section{Abstract}

We propose here a discussion about rural population as the object of policies and practices in the Public Health field. We are interested in identifying if, when, in what ways, and in what economic, political and ideological contexts it received or has been receiving, from public institutions, specific health services and/ or actions. To achieve this, we focus on the policies that combat malaria, still recognized, nowadays, as the endemic of widest impact on the rural population of the Amazon region. This is, therefore, a discussion about the trajectory of the endemics control policies in Brazil (in the context of the health policies' trajectory), especially about the institutions responsible for their execution, illustrated by empirical data and extracts from interviews we collected in fieldworks in Maranhão - the state with the highest percentage of rural population in Brazil. We conclude with a case study about current data and tendencies concerning malaria in the state, and with some comments about current challenges to its control.

Keywords: Rural Population; Public Health; Malaria; Maranhão.

\section{Introdução}

Subsumindo toda a discussão em andamento no campo das Geociências e das Ciências Sociais sobre a relatividade das fronteiras e a estreita correlação entre os conceitos de urbano e rural, mas sem nela incorrer, o objetivo deste artigo é bem mais específico: problematizar a população dita rural como objeto de políticas e ações específicas no campo da Saúde Pública.

Para, além do balizamento desta discussão a partir de uma revisão histórica (Santos, 1985; Merhy, 1987; Moraes, 1990; Bastos, 1991; Gerschman, 1995; Hochman, 1998; Mendes, 1999; Vasconcellos, 2000; Varga, 2002; Silva L. J., 2003; Silva A. R., Varga e Alecrim, 2005), propiciar sua ilustração com dados empíricos, enfocamos, como Silveira e Rezende (2001) e Camargo (2003), as políticas de enfrentamento da malária (considerada ainda hoje a endemia de maior impacto sobre a população rural da Amazônia), aqui problematizadas a partir de dados e depoimentos colhidos em trabalhos de campo no Maranhão.

Embora pertinentes ao tema, não abordaremos, neste artigo (em função das limitações de espaço): o Programa de Saúde da Família (e os diversos problemas em sua implantação junto a comunidades rurais), nem as iniciativas e perspectivas de segmentos e comunidades da própria população rural, enquanto sujeitos de políticas, ações e controle social no campo da Saúde Pública (Silva, 1975; Dias, 1998; Dias, 1999; Varga, 2002, 2003). Estes são objetos de outros trabalhos, já em projeto.

\section{Campanhismo}

A repressão às várias rebeliões populares do século XIX e, sobretudo, o grande impacto da campanha contra Canudos (destruída em 1897), ainda estavam, no início do século XX, muito vivos na memória e radicavam-se no imaginário da população, aguçando a percepção (política) dos sertões como "elo frágil da nacionalidade" (Hochman, 1998). Editava-se, assim, um novo surto de "desbravamento" do território nacional, e o período de 1900 a 1930 (Vasconcellos, 2000) assistiria a várias expedições pelos imensos "sertões" do país - incluindo as "expedições sanitárias", de cunho científico, voltadas especificamente à realização de diagnósticos sobre a situação de saúde dos povoados do interior e à indicação de medidas para melhorá-la. 
A urbanidade francesa (a cultura, as ciências, a educação, a etiqueta, a língua, a moda) materializava o paradigma da modernidade a que aspiravam as elites brasileiras da época, e em que se inspiraria seu projeto urbanístico para a capital da República (Hardman, 1988; Sevcencko, 1993 e 2003). Ao longo do século XX, entretanto, a influência americana entre as elites e o aparelho de estado brasileiro cresceria rapidamente, como veremos, e seria hegemônica já após a Primeira Guerra Mundial.

O século XX iniciava com o auge da economia cafeeira no Sudeste (em que se assentara o eixo central da economia e da política nacional), e da economia da borracha na Amazônia. Coerente como esse modelo econômico agro-exportador, a política de saúde do governo federal centrava-se na vigilância dos portos e na proteção ao ascendente fluxo de imigrantes europeus.

Grandes e freqüentes epidemias nas cidades portuárias ameaçavam todo o comércio exterior brasileiro, pelo risco de as tripulações de navios cargueiros contaminarem-se ao nelas fundearem. Neste campo do combate às endemias é que se insinuaria, inicialmente, a influência americana nas políticas do Estado brasileiro; o combate às doenças constituía-se como exercício da nacionalidade (a consolidação do "paradigma da interdependência" - Hochman, 1998), com a priorização, porém, do saneamento dos portos, dos espaços de circulação de mercadorias e dos de sua produção.

Em 1901, o milionário do petróleo, John D. Rockefeller, criava, nos Estados Unidos (EUA), a Comissão Sanitária Rockefeller, para erradicar a ancilostomose e a malária no sul do país, em função de seu interesse em expandir sua Standart Oil Company para o mercado e o exército da mão-de-obra do Sul. Tendo sido bem sucedida, a Comissão Sanitária Rockefeller passou a desenvolver um modelo de intervenção baseado no combate aos vetores das doenças endêmicas (Vasconcellos, 200o).

Em 1902 era criada a Oficina Sanitária Internacional, que já indicava a necessidade de cooperações multilaterais entre os países americanos para o controle das grandes endemias nas três Américas. No mesmo ano, era instituída a notificação compulsória de endemias (tifo, cólera, febre amarela, peste, varíola, difteria, febre tifóide, tuberculose e lepra).
Em 1904 realizava-se, no Rio de Janeiro, a primeira Convenção Sanitária Internacional, na qual o Brasil foi representado por Oswaldo Cruz e Azevedo Sodré. Nesta convenção se estabelecia um protocolo de medidas de vigilância e de controle de endemias nos portos dos países signatários. Em novembro do mesmo ano, a publicação da lei que Oswaldo Cruz conseguira aprovar pelo Congresso, efetivando a vacinação contra a varíola (com novas e rigorosas cláusulas que previam multas aos refratários, a exigência de atestado para matrículas em escolas, para acesso a empregos públicos, para casamentos, viagens; por isso foi qualificada de "despotismo sanitário" pelo Apostolado Positivista) desencadearia, na capital da República, a chamada Revolta da Vacina.

Como se sabe, à truculência das ações das "brigadas sanitárias” de Oswaldo Cruz (apelidado popularmente de "general mata-mosquitos") associaram-se a truculência das ações de destruição dos cortiços e desalojamento compulsório (sem qualquer apoio para realojamento) de milhares de trabalhadores do centro da cidade, grande maioria dos quais negros ex-escravos, lideradas pelo Prefeito, o engenheiro Pereira Passos (apelidado de "bota-abaixo"). Denomina-se "campanhismo" a esta concepção militarizada e emergencial de enfrentamento de endemias, baseadas nas ainda hoje chamadas "campanhas".

Segundo Sevcenko (1993), as vítimas da Revolta da Vacina não devem ser computadas apenas entre os mortos e feridos nas ruas. Milhares de prisioneiros, após um período de reclusão, espancamentos e maustratos sistemáticos na Ilha das Cobras, eram despachados para as frentes seringalistas do Acre (o que pode fazer supor uma certa dose de remorso no interesse posterior de Oswaldo Cruz pela sorte dos homens incorporados ao "exército da borracha" e, posteriormente, às mortíferas frentes de trabalho da construção da Estrada de Ferro Madeira-Mamoré, entre 1907 e 1912 - Hardman, 1988).

\section{Influências Norte-Americanas}

Em 1910, Abraham Flexner, pedagogo americano formado na The John Hopkins University, publicava um relatório, encomendado pela The Carnegie Foundation for the Advancement of Teaching, acerca da situação do ensino, especialmente, do ensino médico, nos EUA 
e no Canadá. O chamado "Relatório Flexner" propunha uma reforma radical no modelo de ensino da medicina até então adotado, de inspiração francesa.

Flexner, analisando as tendências do mercado profissional para os médicos, com a rápida urbanização e industrialização da economia americana, propunha, entre várias outras medidas, que o laboratório passasse a ser o ambiente central do ensino, com a criação do chamado ciclo básico: os primeiros anos do ensino médico seriam preenchidos com as disciplinas laboratoriais, de modo que transcorreriam integralmente nesse ambiente. $\mathrm{O}$ ensino seria menos personalizado, menos dependente da convivência direta com os pacientes e com os preceptores (como no modelo francês), direcionando mais precocemente os estudantes às "especializações" - o que solucionaria o saturamento do mercado das grandes cidades pelos médicos "generalistas".

O referencial político-ideológico em que se inseria e inspirava o modelo médico-sanitário de Flexner mostrava-se, de modo especialmente revelador, nas suas referências à questão da formação dos médicos negros, e às diferentes políticas a serem adotadas na administração do mercado médico nas grandes cidades e nas zonas rurais (Varga, 2002; Silva e col., 2005). A atenção médica do negro jamais poderá ser deixada unicamente a cargo de médicos negros. Contudo, se o negro puder ser levado a sentir uma forte responsabilidade pela integridade física de seu povo, a perspectiva de seu progresso mental e moral será distintamente abrilhantado. A clínica do médico negro deverá limitar-se a sua própria raça [...] O bem-estar físico do negro não é só oportuno para o próprio negro. Dez milhões deles vivem em estreito contato com sessenta milhões de brancos. O negro não está apenas ele próprio acometido de ancilostomose e tuberculose; ele as transmite aos seus vizinhos brancos, precisamente como os ignorantes e infortunados brancos os contaminaram. [...] O negro deve ser educado não somente em seu próprio interesse, mas para o nosso. [...] Se [...] estes homens puderem ser imbuídos com um espírito missionário eles receberão o diploma com uma missão para servir modesta e devotamente o seu povo, assim exercendo um papel importante na higiene e na civilização de toda a nação. Seu dever chama-os para longe das grandes cidades, para o povoado e a plantation [...] (Flexner 1972, p. 180 - tradução do autor).
Em 1913, era criada a The Rockefeller Foundation que, sob a orientação de Flexner, secretário de seu Conselho Geral de Educação até 1916, passaria a apoiar a fundação de várias escolas com o objetivo de desenvolver novas técnicas e fundamentos para a Higiene (Novaes, 1989).

A Fundação Rockefeller também começou a planejar e organizar suas próprias "expedições sanitárias" pela América Latina e, em 1915, realizava a primeira delas para o Brasil.

A influência desse modelo americano de ensino e organização de serviços de saúde no panorama político-institucional brasileiro se intensificaria, sobretudo, após a Primeira Guerra Mundial (1914-1918), quando os EUA ganharam grande projeção internacional e consolidaram sua hegemonia econômica, especialmente em relação à América Latina.

No Brasil, o campo da Saúde Pública, já nesta época, polarizava-se no debate entre os que defendiam a centralização e padronização das ações do controle de endemias pelo Governo Federal, entre os quais se destacava o maranhense Nina Rodrigues, e os que defendiam que esta seria uma atribuição dos estados, entre os quais se destacava o carioca Azevedo Sodré (que mudaria de posição em 1918); era fundada a Liga Pró-Saneamento e lançada a campanha pelo saneamento dos sertões.

Em 1917, iniciava-se, assim, a cooperação com o International Health Board, da Fundação Rockefeller, no combate à febre amarela e na formação de médicos sanitaristas. A Fundação Rockefeller financiou 70 bolsas de estudos para médicos brasileiros na The John Hopkins University, e a criação do "Instituto de Hygiene e Saúde Pública de São Paulo”. Nesse contexto, realizava-se a reforma dos serviços sanitários e a promulgação do código sanitário rural em São Paulo, sob Artur Neiva.

Em 1918 eram criados o Serviço de Medicamentos Oficiais e o Serviço de Profilaxia Rural, ligados à Diretoria Geral de Saúde Pública. Esse ano seria marcado pelo início da epidemia de gripe espanhola, entre setembro e dezembro, que causaria de 30.000 a 180.00o mortes no Brasil.

Em 1919, em medida coerente com a importância secundária da população rural para a política de saúde do Governo, o Serviço de Profilaxia Rural passava da alçada da Diretoria Geral de Saúde Pública para a 
do Ministério da Justiça e dos Negócios Interiores, pasta sob responsabilidade do maranhense Urbano Santos.

O Presidente Epitácio Pessoa planejava uma reforma geral nos serviços sanitários, que se materializou a partir da criação do Ministério da Saúde e Instrução Pública. Em 1920, Carlos Chagas assumia o Departamento Nacional de Saúde Pública, criando a Diretoria de Saneamento e Profilaxia Rural e a Inspetoria de Lepra e Doenças Venéreas (Vasconcellos, 200o).

O campo da Saúde Pública polarizava-se, então, entre duas posições: uma via nas cidades e na priorização ao avanço da urbanização a perspectiva da conquista da modernidade, e a outra pretendia o resgate da nacionalidade a partir da abordagem prioritária de seu elo mais frágil: os sertões. Oswaldo Cruz, um dos luminares da primeira corrente, desde o início do século, passava para o segundo grupo.

\section{O Modelo Americano e a "Refoma Sanitária"}

A expressão "reforma sanitária" passou a ser utilizada, no Brasil quando médicos de algumas das maiores cidades do país (Rio de Janeiro, São Paulo, Belo Horizonte) começaram a propugnar uma mudança radical nos métodos até então adotados na condução da Saúde Pública (Merhy, 1987; Varga, 2002; Silva e col., 2005).

Esses médicos opunham-se ao modelo do campanhismo militarista de Oswaldo Cruz e do Departamento Sanitário Federal no combate às epidemias. Essa oposição marcou toda uma geração de médicos que, envolvidos na condução dos serviços de saúde de suas cidades e/ou estados, passaram a propor e a adotar outros métodos, como Geraldo Horácio de Paula Souza (formado na The John Hopkins University, em que se formara Flexner) que, na São Paulo de 1922, realizaria a sua "reforma sanitária", já inspirado no modelo americano de organização de serviços de saúde (Merhy, 1987).

Como comentamos em Varga (1996), esse modelo calcava-se em teorias em voga no campo das Ciências Sociais americanas da época, para as quais as doenças mais comuns entre as classes sociais subalternas eram resultantes de uma cultura da pobreza e da ignorância ${ }^{1}$ decorrente, reprodutora de hábitos insalubres. Era necessário, assim, o reconhecimento dos fatores socioeconômicos que determinariam essa cultura, para definir as estratégias a serem adotadas para vencer as barreiras culturais e induzir essa população mais pobre (que além de ignorante e supersticiosa era tida como desorganizada) a aderir pacificamente às recomendações e medidas propostas pelos programas oficiais de saúde, o que contribuiria também para reintegrá-la à sociedade; justificava-se, assim, a adoção da chamada "educação sanitária" entre suas estratégias básicas (Merhy, 1987).

Entendida como um dos fundamentos da então moderna Saúde Pública, definia-se educação sanitária, portanto, como o processo de criação de uma "consciência sanitária" na população, por meio da instrução da clientela dos "Centros de Saúde" sobre noções e "hábitos de higiene" (Serviço de Educação em Saúde Pública, 1986).

Ao assumir, em 1922, a direção do Serviço Sanitário Estadual de São Paulo, Paula Souza tornava-se, assim, o principal interlocutor brasileiro do modelo americano de organização de serviços de saúde.

Representando oficialmente a Fundação Rockefeller durante o "I Congresso da Sociedade Brasileira de Higiene”, em 1923, Paula Souza propôs uma mudança dos princípios da Saúde Pública até então praticada, para uma administração baseada "em metodologia científica”, envolvendo aproximação maior entre a Faculdade de Medicina e o Serviço Sanitário - movimento que já resultara na criação do Instituto de Hygiene, e que culminaria, posteriormente, na fundação da Faculdade de Hygiene e Saúde Pública da Universidade de São Paulo (Merhy, 1987). Também o modelo de organização de serviços de saúde, por ele então proposto, respaldava-se em sua experiência com os trabalhos desenvolvidos em São Paulo, consistindo na implantação de postos municipais de saúde, em que equipes multiprofissionais prestariam serviços de "atenção integral à saúde" (com destaque para as ações denominadas de "educação sanitária").

Nos debates em curso no campo da Saúde Pública, Afrânio Peixoto, preocupado com os problemas de saúde da própria capital, comentava as dificuldades 
em delimitar o universo urbano do rural: “(...) Porque, não nos iludamos, o 'nosso sertão' começa para os lados da Avenida” (Vasconcellos 200o, p. 43).

O campo da Saúde Pública expandia-se, envolvendo vários setores da sociedade, de modo que, ao longo da década de 1920, o movimento operário, enquanto organizava fundos de greve e de assistência aos trabalhadores, também se apropriaria de discursos do campo da Saúde Pública (Vasconcellos, 200o).

Em 1923, expressando a crescente influência do modelo americano e da experiência de São Paulo, eram criados o Serviço de Propaganda e Educação Sanitária, e Inspetoria de Higiene Industrial e Profissional, no Departamento Nacional de Saúde Pública. A Lei Eloy Chaves criava as Caixas de Aposentadoria e Pensão (CAP). Nascia, assim, a Previdência Social, sob custeio tripartite: trabalhadores-patrões-governo. Nesse mesmo ano, a Oficina Sanitária Internacional passava a denominar-se Oficina Sanitária Panamericana (Mendes, 1999).

Em 1924, 21 repúblicas americanas ratificavam, em Havana, o Código Sanitário Internacional.

Entre 1926 e 1928 novos surtos de febre amarela e de varíola se alastraram pelo Distrito Federal, acarretando um desgaste político da Fundação Rockefeller, que comandava a Comissão de Febre Amarela.

A partir de 1929 o governo começou a ser pressionado para que os cargos em instituições de saúde pública passassem a ser atribuídos especificamente aos médicos sanitaristas.

No primeiro governo de Vargas (1930-1945) as CAP foram extintas, sendo substituídas pelos Institutos de Aposentadoria e Pensão (IAP), cujo custeio se reduziu a participação de verbas federais, segundo uma política de capitalização (“contencionista” - Mendes, 1999, p. 21) da Previdência Social, na qual a assistência médica também passaria a ter importância secundária. Com a industrialização e a progressiva perda de importância do componente agro-exportador da economia, configurava-se e ganhava força o modelo médico-assistencial privatista, enquanto esvaziava-se cada vez mais o campanhismo.

Em 30 de março de 1942 o Congresso americano criava o Institute of Inter-American Affairs (IIAA), destinado a coordenar e a administrar os programas bilaterais de saúde na América Latina. No Brasil, o Ministro da Educação e Saúde, Gustavo Capanema, preparava esses planos de cooperação no campo da saúde (Bastos, 1996) e a chamada Reforma Capanema, com as Leis Orgânicas do Ensino.

Em 1942, em plena Segunda Guerra Mundial, as forças armadas japonesas capturavam as fontes produtoras de borracha, quinino e fibras no oriente, deflagrando, no alinhamento do Brasil com o esforço de guerra dos EUA, um breve impulso ao extrativismo na Amazônia e seu interesse em apoiá-lo. Nascia, assim, a Rubber Reserve Company, posteriormente denominada Rubber Development Organization (Bastos, 1996).

Em 17 de julho de 1943, era firmado um contrato (que teria duração até 31 de dezembro de 1943), posteriormente denominado "Convênio Básico", entre o Ministério de Estado dos Negócios das Relações Exteriores (sob direção de Oswaldo Aranha) com o IIAA, visando à realização de várias ações e programas de saúde e saneamento. A primeira cláusula deste convênio criava o Serviço Especial de Saúde Pública (SESP), com as seguintes atribuições (note-se a referência explícita ao saneamento do vale do Amazonas, área de interesse estratégico, na ocasião, para os EUA): 1. O saneamento do Vale do Amazonas, especialmente a profilaxia e os estudos de malária no vale e a assistência médico-sanitária aos trabalhadores ligados ao desenvolvimento econômico da região.

2. O preparo de profissionais para trabalho de saúde pública, compreendendo o aperfeiçoamento de médicos e engenheiros sanitaristas, a formação de enfermeiros de saúde pública e o treinamento de outros técnicos.

3. A colaboração com o Serviço Nacional de Lepra e por intermédio deste, com as repartições sanitárias estaduais, para o combate à Lepra. (Bastos, 1996, p. 32)

O SESP seria superintendido por um médico do IIAA (aceito pelo Ministério), auxiliado por um médico do serviço público federal, como assistente administrativo.

Em outubro de 1943, o SESP passaria à superintendência do Major Einor Christoferson, que criaria o Programa e a Divisão de Lepra, e o Programa e a Divisão de Educação Médica, incluindo a Educação Para a Saúde.

Nesta gestão do SESP, Charles Wagley (antropólogo, autor das primeiras etnografias sobre os índios Tenetehara, do Maranhão e do Pará), passou a exer- 
cer tanto o cargo de Assistente Executivo da Superintendência, quanto o da Divisão de Educação Sanitária (Bastos, 1996).

Integrando os investimentos americanos (também no contexto do esforço de guerra) na reconstrução da Estrada de Ferro Vitória-Minas, visando intensificar a produção de minério de ferro, o SESP também foi envolvido nas atividades de saneamento do vale do rio Doce. Prorrogava-se, assim, por mais 5 anos, o contrato do Governo brasileiro com o IIAA, até 31 de dezembro de 1948.

Em 1944, a superintendência do SESP era transferida para um médico brasileiro. Em 1945, o DecretoLei ${ }^{0} 1.099$, de 28 de novembro, estabelecia a carreira de médico-sanitarista.

Em 1946, com a nova Constituição, era também promulgada a Lei de Diretrizes e Bases da Educação Nacional e criados os Planos de Valorização Econômica.

Em 1947, a Oficina Sanitária Panamericana constituía-se como Organização Sanitária Panamericana.

Em janeiro de 1949 era renovado o convênio com o IIAA, prorrogado até junho de 1955. Nesse ano, por solicitação dos respectivos governos estaduais, o SESP começou a atuar na área de produção de cacau, na Bahia; de produção de açúcar, em Pernambuco; e de produção de sisal, na Paraíba.

Em 1950, o SESP era instado a atuar no vale do São Francisco, junto a comunidades carentes em áreas de grande pobreza, o que marcaria o início de uma nova modalidade de envolvimento da instituição, até então condicionado à articulação direta com frentes de expansão².

Significativamente, a partir de então, se verifica uma diminuição nos investimentos americanos no SESP, com um progressivo aumento dos investimentos brasileiros e a atuação do SESP experimentaria uma rápida expansão: em 1952, iniciava sua atuação no Rio Grande do Sul e, em 1953, com a instalação, em Belém, da Superintendência do Plano de Valorização da Amazônia, o SESP passou a atuar em Goiás, Mato Grosso e no Maranhão (Varga, 2002; Silva e col., 2005).

A Lei $n^{0} 1.920$, de 25 de julho deste ano, criava o Ministério da Saúde, ao qual ficariam vinculados o Departamento Nacional de Saúde, responsável pelo combate à febre amarela, malária e peste, e a Divisão de Organização Sanitária, responsável pelo combate à bouba, esquistossomose e tracoma. Em 1954, o SESP assumia o Ceará; em 1955 o Sergipe e o Paraná.

Em 1956 era criado o Departamento Nacional de Endemias Rurais (DeNERU), que incorporaria os programas de controle de endemias até então existentes, subordinados ao ex-Departamento Nacional de Saúde e à ex-Divisão de Organização Sanitária. Neste ano, o SESP passaria a atuar no Rio Grande do Norte e no Piauí, também expandindo sua área de atuação no Espírito Santo; em 1957, em São Paulo, através do Serviço Social da Indústria; em 1958, no Rio de Janeiro e Santa Catarina (Bastos, 1996).

Em 9 de abril de 1959 o Decreto n $45 \cdot 771$ atribuía ao Ministério do Exército a responsabilidade pelo povoamento ao longo da rodovia Belém-Brasília, no trecho de 450 quilômetros entre Guamá e Imperatriz, no qual o SESP foi convocado a implantar unidades sanitárias.

O SESP, em 196o, transformava-se em Fundação Serviço Especial de Saúde Pública (FSESP), com o fim da cooperação com os EUA, e passava a vincular-se ao Ministério da Saúde (Bastos, 1996).

Em 1963, estabeleciam-se, na III Conferência Nacional de Saúde, as bases teórico-ideológicas do "modelo médico-assistencial privatista”, como expressão da hegemonia alcançada pelas proposições do chamado "movimento municipalista articuladas pelo sanitarismo desenvolvimentista" (Mendes, 1999, p. 29): a constituição de um subsistema estatal, de um subsistema privado contratado e conveniado, de um subsistema privado de atenção médica supletiva, e de um subsistema de alta tecnologia. O subsistema estatal se caracterizaria pelo exercício de uma "medicina simplificada destinada à cobertura nominal de populações não integradas economicamente e as ações de saúde pública" (Mendes, 1999, p.3o) - caso das comunidades rurais.

Em 1965, era criada a Campanha de Erradicação da Malária (CEM), independentemente do DeNERU.

Os IAP seriam extintos e incorporados pelo Instituto Nacional de Previdência Social, em 1966, com a uniformização dos benefícios a trabalhadores urba-

\footnotetext{
2 Conforme consta da alínea a) do artigo $2^{\circ}$ de seus Estatutos: "organizar e operar serviços de saúde pública e assistência médicohospitalar nas áreas do território nacional onde se desenvolvem ou venham a se desenvolver programas de valorização econômica, sempre que tais serviços não constem dos programas de órgãos federais” (Bastos, 1996, p. 491).
} 
nos (processo que se consolidou na década de 1980, e que veio a ser denominado de "universalização excludente" - Mendes, 1999, p.23). Consolidava-se, assim, a hegemonia do modelo médico-assistencial privatista, tendo o Estado como grande financiador do sistema, as empresas privadas de saúde como as maiores prestadoras de serviços ao Estado, e as empresas inter ou multinacionais como principais fornecedoras de equipamentos, medicamentos e outros insumos.

Nesse mesmo ano era criada a Campanha de Erradicação da Varíola, subordinada ao Ministério da Saúde e dirigida por pessoal do quadro da FSESP que, em crise financeira, passou a ter acesso aos recursos da Sudene, da Sudam, do INPS e do Funrural.

Em 1969, a Fundação Serviço Especial de Saúde Pública era transformada em Fundação Serviços de Saúde Pública, passando a ser regida por novo estatuto.

Em 22 de maio de 1970, o Decreto nº 66.263 criava a Superintendência de Campanhas de Saúde Pública (Sucam), a partir da fusão do ex-Departamento Nacional de Endemias Rurais (DeNERU), da ex-Campanha de Erradicação da Malária (CEM) e da ex-Campanha de Erradicação da Varíola (Moraes, 1990).

\section{Movimento pela Reforma Sanitária}

Ao longo da década de 1970, estimulados e apoiados pela OPAS, vários Departamentos de Medicina Preventiva seriam criados nas universidades e passariam a se constituir em espaços importantes na construção das bases teórico-metodológicas e na articulação do movimento contra-hegemônico ao modelo privatista, o que configuraria o autodenominado Movimento pela Reforma Sanitária dos anos 1970-1980. Surgiram, no período, vários movimentos de trabalhadores de saúde, em que se destacaram os das entidades sindicais médicas.

Os atores do Movimento pela Reforma Sanitária, embora marcassem posição, explicitando e denunciando as diferenças entre suas propostas e as ações do Estado, propunham a negociação com os representantes do governo. A estratégia adotada, para tanto, foi a de buscar aproximação e estabelecer alianças com funcionários de nível intermediário na burocracia do estado, buscando sua colaboração para desencadear discussões acerca da concepção de saúde, no interior de suas instituições (com vistas a um redimensiona- mento de seus determinantes), e para o repasse de informações e documentos estratégicos para estabelecer algum nível de controle social sobre as políticas de saúde (Gerschman, 1995; Mendes, 1999).

Em 1971, a Previdência, que já assumia a gestão de políticas de saúde e de assistência distintas para diversos segmentos da população, cristalizava a discriminação entre a população urbana e a rural, através da instituição do Programa de Assistência ao Trabalhador Rural (Prorural), gerido pelo Funrural (Mendes, 1999).

Em 1974, era criado o Ministério da Previdência e da Assistência Social (MPAS), resultado da separação da área da previdência da do trabalho, e sua empresa de processamento de dados, o Dataprev. Lançava-se o Plano de Pronta Ação (PPA), universalizando o atendimento às urgências, acarretando a multiplicação das formas de contrato da Previdência com prestadores privados.

$\mathrm{O}$ ano também foi marcado pelo fortalecimento de vínculos com os hospitais universitários, através do Protocolo MPAS-MEC, de 23 de outubro, e pela instituição do Fundo de Apoio ao Desenvolvimento Social, que passaria a subsidiar empresas privadas na construção de hospitais, que proliferariam, durante as décadas de 1970 e 1980 (Gerschman, 1995; Mendes, 1999).

Em 1975, a Lei no 6.229, do Sistema Nacional de Saúde, institucionalizaria esse modelo médico-assistencial privatista, estabelecendo atribuições e competências específicas de instituições públicas e privadas ("atenção à saúde coletiva” e "atenção à saúde das pessoas", respectivamente), e mecanismos e instâncias de integração e coordenação geral.

Em 1976, era criado o Programa de Interiorização das Ações de Saúde e Saneamento no Nordeste (PIASS), primeiro programa federal de medicina simplificada (Mendes, 1999). Nesse mesmo ano, era fundado o Centro Brasileiro de Estudos em Saúde (Cebes), que passaria a ter um importante papel na articulação do chamado Movimento pela Reforma Sanitária.

Em 1977, era criado o Sistema Nacional da Previdência Social (Sinpas) e o Instituto Nacional de Assistência Médica da Previdência Social (Inamps), assim como as carreiras de Sanitarista e Agente de Saúde Pública visando, principalmente, produzir quadros técnicos para a execução do PIASS e o preenchimento dos cargos do Inamps. 
Entre 1977 e 1978, as Portarias no $360 / 77$ e no 204 / 78 estabeleciam o caráter consultivo e normativo do Conselho Nacional de Saúde (Dias, 1999, p. 110).

Em 1978, realizava-se a Conferência Internacional de Saúde de Alma-Ata, cujas propostas de cuidados primários à saúde vinham ao encontro do Movimento pela Reforma Sanitária e o instrumentalizariam na reafirmação da necessidade das políticas compensatórias do Estado, voltadas aos grupos sociais excluídos. Como resultado deste processo, em 1979, o PIASS seria estendido a todo o país, o que determina grande expansão da rede ambulatorial pública.

Em 1979, era fundada a Associação Brasileira de Saúde Coletiva (Abrasco). 0 Cebes e a Abrasco passariam a protagonizar um crescente movimento contrahegemônico à política de saúde do Governo, consolidando o Movimento pela Reforma Sanitária (Gerschman, 1995; Mendes, 1999).

No Maranhão, esse período, correspondente ao governo do médico Osvaldo da Costa Nunes Freire (31/ 3/1975-15/3/1979), também seria marcado pela emergência local do Movimento pela Reforma Sanitária, que realizaria uma avaliação pública da gestão anterior, concluindo que apenas a extensão de serviços e capacitação/atualização de pessoal tiveram algum resultado, e denunciando a proliferação de convênios com serviços privados de saúde.

Em 1978, com o início da implantação do Projeto Ferro Carajás, a FSESP era mobilizada para a implantação de serviços de saúde em povoados rurais de sua área de influência, com o objetivo de integrar o conjunto de medidas de amortecimento de tensões sociais na região conflagrada pela chamada Guerrilha do Araguaia, concomitantemente à sua repressão militar: Então em [19]77 eu fui a São Paulo, fazer o curso de Saúde Pública da USP, da Faculdade de Saúde Pública de São Paulo (...) $E$ de lá... (...) fui ser diretor do $S E S P$ em Goiás, porque o SESP, ele tinha recebido as Unidades, aliás, tava construindo as Unidades do Bico-doPapagaio... (...) a Vale do Rio Doce, quando implantou... quando implantou lá a... (...) extração de ferro, né? quando descobriu a reserva, então... ao longo da rodovia... e aquelas cidadezinhas que eles identificavam como áreas de tensões, e que futuramente ia explodir, devido [a]o incremento e à presença da ferrovia, ele instalava (...) Também área da revolução, áreas de tensões sociais, área... daquelas áreas de... onde houve aquelas guerrilhas, tal... então a Fundação, em parceria com a... com a Vale do Rio Doce, com a Vale, né? para dar suporte àqueles postos que as cidades que iriam surgir com a implantação da... da ferrovia, e também no norte de Goiás, então era o Bico-de-Papagaio que hoje está no estado de Tocantins, com a cisão do estado, né? eu permaneci um ano lá, gerenciando o setor saúde, que era as Unidades Mistas da Fundação, né? construção e fazendo funcionar as Unidades Mistas, né? em Tocantinópolis, e aquelas de Xambioá, Araguatins, tal... e aqueles Centros de Saúde..." (Jorim Severino Ithamar, em entrevista realizada em 20/12/20oo, na sede da Funasa, em Jordoa, em São Luís/MA, p.1-2).

Em 1980, realizava-se a VII Conferência Nacional de Saúde, cujo tema foi a implantação de uma rede básica de serviços de saúde. Com base na VII Conferência e na experiência do PIASS, surgia o Programa Nacional de Serviços Básicos de Saúde (Prev-saúde), encomendado a um grupo técnico interministerial e à OPAS, que visava à universalização dos cuidados primários à saúde, em todo o território nacional. Sua primeira versão foi bastante criticada, a ponto de uma segunda versão ter sido elaborada e encaminhada à Comissão de Saúde da Câmara dos Deputados, sem resultado (Mendes, 1999).

Entre 1981 e 1982, com a política econômica recessiva, o componente médico-assistencial passa a ser identificado como um dos principais causadores da crise financeira da Previdência. Os prestadores privados do subsistema contratado e conveniado, e de atenção médica supletiva, passaram a ser questionados e fiscalizados de modo mais rígido pelo Estado e estabelecia-se uma aliança tática entre técnicos ligados ao Movimento pela Reforma Sanitária (que passavam a ocupar cargos no Inamps) e os dirigentes (liberais) da instituição.

Em setembro de 1981, era criado o Conselho Consultivo da Administração de Saúde Previdenciária (Conasp), que coordenaria todo o sistema. O Conasp era politicamente apoiado pelo Movimento pela Reforma Sanitária, pelos médicos autônomos e pela Associação Brasileira de Medicina de Grupo, polarizando com a oposição da Federação Brasileira de Hospitais. Por meio do Plano de Reorientação da Assistência à Saúde, ele propunha que a função normatizadora da atenção médica passasse do Ministério da Saúde para o Inamps, com a reversão gradual do modelo 
médico-assistencial “(...) através do aumento da produtividade do sistema, da melhoria da qualidade da atenção, da equalização dos serviços prestados às populações urbana e rural, da eliminação da capacidade ociosa do setor público, da hierarquização dos equipamentos, da criação do domicílio sanitário, da montagem de um sistema de auditoria médicoassistencial e da revisão dos mecanismos de financiamento (...)" (Mendes, 1999, p.36).

Em 1983, tomavam posse novos prefeitos compromissados com a descentralização da política de saúde, e ganhavam força as propostas de municipalização. Entre 1983 e 1985, como desdobramento do Plano de Racionalização Ambulatorial, do Conasp, configurava-se e consolidava-se o programa das Ações Integradas de Saúde (AIS), do Inamps. Serviços privados e públicos de saúde passavam a ser considerados "prestadores de serviços” ao sistema (Gerschman, 1995; Mendes, 1999).

O Simpósio da Comissão de Saúde da Câmara dos Deputados, de 1984, marcaria o início da gestação da proposta do SUS. Em 7 de junho de 1985, estabeleciam-se as bases legais das AIS.

O campo da Saúde Pública do período já estava polarizado pela disputa entre as posições políticas que privilegiavam a tática de ocupação do espaço institucional, e as que privilegiavam a acumulação de poder de articulação e mobilização na "sociedade civil", "para enfrentamento do projeto neoliberal" (Mendes, 1999, p. 39).

Entre 1985 e 1986, com o fim da ditadura militar e o advento da chamada "Nova República", sob pressão de políticos e da própria Presidência da República, o Inamps passaria a privilegiar convênios com entidades filantrópicas, fortaleceria sua própria burocracia e quadros, aumentando os gastos com o setor público e com o setor de alta tecnologia (Mendes, 1999).

Em março de 1986 realizava-se a VIII Conferência Nacional de Saúde. Constituindo-se um marco no campo da Saúde Pública, o processo de organização da VIII Conferência diferiu das anteriores pela ampla representação e participação de representantes de forças sociais, e pelo processo ascendente de realização. Nessa Conferência era enunciado o projeto do Sistema Único de Saúde, tendo por princípios a integralidade, a universalidade, a hierarquização, a descentralização e o controle social - expressão do modelo contra- hegemônico, do Movimento pela Reforma Sanitária (Mendes, 1999).

Aumentava a tensão política entre o Ministério da Saúde e o da Previdência e Assistência Social e, em 1987, era instituído o Sistema Unificado e Descentralizado de Saúde, o SUDS (Mendes, 1999); suas unidades básicas seriam os Distritos Sanitários, abrangendo 25.000 a 40.000 pessoas, com sistema de referência e contra-referência, operacionalizados segundo os princípios da universalidade no acesso, da resolutividade, da continuidade (já se falava no "médico de família”) e integração das ações (Sousa, 1996). A proposta foi apresentada por intelectuais do Ministério da Saúde como um avanço sobre as Ações Integradas de Saúde, uma vez que previa o repasse não só de recursos financeiros, mas também da rede física de serviços de saúde.

Entre 1987 e 1988, na gestão Hésio Cordeiro, preparava-se a transição SUDS-Sistema Único de Saúde (SUS), e o processo de "desestabilização programada" do Inamps (Mendes, 1999, p.44), com o fortalecimento do setor público e o aumento na fiscalização do setor privado. Enquanto a Sucam e a FSESP resistiam a engajar-se no processo de descentralização, o Inamps, sob a gestão de Hésio Cordeiro, dava um salto nesse sentido.

\section{Sistema Único de Saúde (SUS)}

A Constituição de 1988 instituiu o SUS. Entre 1988 e 1990, no entanto, durante a Presidência de José Sarney, restabeleciam-se os "anéis burocráticos" (Mendes, 1999, p.45) e os vínculos clientelísticos do Inamps, sob a alegação da correção dos desvios da gestão anterior, com municipalização seletiva e a pouca valorização (e conseqüente esvaziamento) da proposta dos Distritos Sanitários como modelo assistencial, e o reforço da universalização excludente.

Em 1990, já sob a Presidência de Fernando Collor de Melo, era promulgada a chamada "Lei orgânica do SUS": a Lei n 8.080 (com vetos da Presidência da República em todos os artigos que tratavam da instituição das Conferências e dos Conselhos de Saúde). Em dezembro, após reação de entidades da sociedade civil (articuladas em torno da Plenária da Saúde), era promulgada a Lei ${ }^{0} 8.142$, que trata das Conferências e dos Conselhos de Saúde, revertendo os vetos de Collor. 
Ao longo dos anos 1990, entretanto, o projeto privatista seria revigorado, em todo o país, com uma espécie de reedição das CAPs, com o fortalecimento dos "convênios" com as empresas de medicina, reafirmando a hegemonia do subsistema de atenção supletiva (“medicaid à brasileira”, segundo Mendes, 1999, p.53).

Em 1991, a FSESP, a Sucam e o Dataprev (a empresa de processamento de dados da Previdência) seriam extintos e fundidos na Fundação Nacional de Saúde (Funasa) que, criada com uma cota de cargos (remunerados) de confiança bem menor que a soma dos anteriormente disponíveis para as três instituições, já nascia em meio a uma disputa interna entre os funcionários por eles, cristalizando uma rivalidade corporativista que perdura até nossos dias 3 .

A Funasa herdou da FSESP o que chamaremos aqui de sanitarismo "integralista", a experiência na implantação, articulada a grandes projetos de desenvolvimento, de redes de serviços (de saúde, saneamento e abastecimento de água) orientados pela perspectiva de uma atenção integral à saúde. A FSESP também foi responsável pela formação de várias gerações de médicos generalistas: egressos das faculdades de medicina, os médicos de seus quadros tinham uma carreira bem definida no órgão, que se iniciava nas Unidades Mistas (UMs) ${ }^{4}$ mais remotas, e que incluía estágios de capacitação prática em todos os setores do serviço, do centro cirúrgico à administração:

Faziam tudo. As Unidades Mistas era...... aquilo é uma atenção ao indivíduo como um todo. Então a Unidade Mista o que é? É um Centro de Saúde de referência ...e uma retaguarda hospitalar... de leitos....geralmente a Unidade Mista ela está dentro de uma cidade [de] maior porte. Então ela tomava conta daquela cidade onde ela estava instalada, e ela tinha uma responsabilidade com as demais pequenas. Porque as visitadoras referenciavam.... cada Posto de Saúde era composto de uma visitadora e de um auxiliar de saneamento, para obras de saneamento, é... indicação e orientação de como construir fossas, e essas coisas, né?
E... a cada semana ia um médico, fazer a assistência médica. Cuidar da... do pré-natal... né? Enfim, era assistência à saúde do indivíduo, doenças transmissíveis etc., etc... tinha também uma formação de parteiras leigas. As parteiras leigas eram controladas pela Fundação. A Fundação dava o treinamento e dava um kit com a bolsa... e era abastecido toda semana com álcool, luvas, com credê, com nitrato de prata e tal. ${ }^{5}$

(...) .o SESP também tinha uma parte poderosa que era o sistema de serviços de engenharia. Então nessas cidades pequenas, onde tinha as Unidades Mistas, tinham também investimentos de abastecimento público de água, que hoje ainda permanece como o forte da Funasa hoje, e vai ser sempre. Com as responsabilidades que o Governo Federal tem através da Funasa, de construção de... para abastecimento de simplificado de água, em até... a população de 20 mil habitantes... né? com ligações domiciliares, etc, etc... E permanece ainda à cargo da Fundação Nacional de Saúde essas atividades. Então o princípio era este. Nas cidades de grande porte, a engenharia fazendo os investimentos dos projetos internos, conseguindo dinheiro a fundo perdido, e criaram os serviços autônomos de água e esgoto. Não era serviço monopolista, como na Caema [Companhia de Águas e Esgotos do Maranhão]. Era um serviço espelhado nos países desenvolvidos, quando o município é responsável pela sua distribuição de água. [...] As doenças... dentro do SESP, as doenças controladas por imunizantes, foi sempre feito bem. Porque tinha seus poderes próprios, e tal, né? O SESP sempre foi uma referência dentro do próprio estado. Talvez a ciumeira por causa disso... porque trabalhava-se bem. Porque tinha aquela... aquela responsabilidade, o povo tinha mais compromisso, né?

A atuação da Sucam, como anunciava o próprio nome da instituição, caracterizou-se pelo que denominaremos de campanhismo popularizado. Suas equipes eram fardadas, submetidas a rígidas hierarquia e disciplina, e preparadas para as condições de trabalho em campo; de grande mobilidade e eficácia, reali-

\footnotetext{
3 Ainda mais agravada a partir de 1999, com a incorporação dos profissionais de saúde da Fundação Nacional do Índio (Funai) pela Funasa, determinada pela Portaria Conjunta ${ }^{\circ}$ 1, de 25/8/1999, das Presidências de ambas instituições (Varga, 2002).

4 As UMs são serviços semi-hospitalares, geralmente dotados de equipe médica composta de clínico-geral, cirurgião geral, ginecologista-obstetra, pediatra e ortopedista; corpo de enfermagem; serviços de radiologia, pronto-atendimento, ambulatório, internação, centro-cirúrgico/obstétrico e laboratório.

5 Entrevista com Jorim Severino Ithamar, Chefe do Setor de Epidemiologia da Funasa/CR-MA, em 20/12/20oo, p. 4-5.

6 Entrevista com Jorim Severino Ithamar, Chefe do Setor de Epidemiologia da Funasa/CR-MA, em 20/12/20oo, p. 5-6.
} 
zavam a busca ativa dos pacientes, mesmo os das comunidades e povoados de mais difícil acesso, que eram cuidadosamente cartografados e tinham seus domicílios e habitantes periodicamente recenseados e recadastrados - motivo porque os dados demográficos, da Sucam, eram considerados mais precisos e confiáveis que os do próprio Instituto Brasileiro de Geografia e Estatística (IBGE). A Sucam era o único serviço público disponível em muitos desses povoados. Entre eles mesmos recrutavam-se funcionários e os capacitavam em nível médio; assim, mantinham e facilmente criavam laços de amizade entre as comunidades em que atuavam, conquistando a simpatia, o respeito e a colaboração da população - estratégia à qual se deve, portanto, em grande medida, seu sucesso operacional. (...) o SESP só trabalhava em unidade assistencial, não é... puramente nas unidades de saúde... em tratamento especificamente sobre o indivíduo. Cuidado específico e ação sobre o indivíduo.... A Sucam não, cuidados específicos sobre a coletividade, em relação às endemias (...)

Porque a Sucam era um órgão de administração direta, né? de nível... Porque as endemias eram pesadas... ... a Sucam sempre trabalhou bem nisso. Sempre trabalhou bem nisso, na parte verticalizada. A Sucam não dava a mínima para os administradores locais, gestores locais, porque a responsabilidade dela era traçar, jogar seus contingentes e sufocar. ${ }^{8}$

É possível perceber nos depoimentos acima a importância da autonomia, tanto da ex-FSESP, quanto da ex-Sucam, em relação aos interesses de políticos locais e regionais, necessária para assegurar o caráter técnico do planejamento e a qualidade das ações executadas - o que, definitivamente, a, na época, recém-fundada Funasa não herdou (Varga, 2002).

Em 1992, no entanto, a IX Conferência Nacional de Saúde determinou a extinção da Funasa, e a incorporação de seus serviços, equipamentos e quadro de pessoal pelas Secretarias Estaduais e Municipais de Saúde.

Diante da grita geral das delegações dos estados amazônicos e nordestinos, que argumentavam (com razão) que, nessas regiões, a Funasa era, freqüentemente, o único serviço de saúde disponível para a maioria da população, políticos, intelectuais e sanitaristas afirmavam que esse processo de absorção da Funasa pelas Secretarias Estaduais e Municipais de Saúde seria gradual, iniciando-se pelos estados do Sul e Sudeste, para apenas lenta e gradualmente chegar à Amazônia e ao Nordeste.

O que se verificou, entretanto, a partir de 1993, não correspondeu a essas expectativas e propostas. Em vários estados do Nordeste e da Amazônia, quer por obediência às ordens superiores de Brasília quer por cumplicidade com políticos e interesses locais, alguns Coordenadores Regionais da Funasa chegaram a se vangloriar de estarem na "vanguarda" do processo nacional de municipalização dos serviços de saúde. Foi o que se deu no Maranhão, por exemplo.

Nesse contexto, o Ministério da Saúde determinou que as ações de vigilância epidemiológica (via projeto "Vigisus"), e aquelas voltadas à saúde de comunidades indígenas, seriam as únicas pelas quais a administração federal, por meio da Funasa, continuaria mantendo responsabilidade direta. As demais atribuições e recursos do órgão seriam todos repassados às esferas estaduais e municipais.

\section{Malária e Políticas de Saúde para a População Rural: um estudo de caso no Maranhão}

Segundo o IBGE, embora a porcentagem de população rural do Maranhão venha diminuindo rapidamente (no censo de 1991 ainda predominava sobre a urbana, perfazendo $59,99 \%$ da população total, e na contagem de 1996, 48,07\%), o Censo Demográfico de 2000 registrou 40,48\% da população maranhense habitando em domicílios rurais: a maior porcentagem do país (IBGE, 2007).

A endemia de maior impacto no Maranhão (como nos estados amazônicos em geral) ainda é a malária, fato nitidamente relacionado com sua grande proporção de população rural, e com sua identidade, mais especialmente da chamada Amazônia maranhense (ou Pré-Amazônia), como principal fornecedor de mão-deobra garimpeira para toda a Amazônia brasileira 9 .

7 Idem, p. 2.

8 Ibidem, p. 10.

9 A relação entre a malária e a atividade garimpeira é bastante conhecida e comentada na literatura técnico-científica brasileira e internacional sobre o assunto. 
Uma pesquisa do Departamento Nacional de Produção Mineral, realizada em 1990, indicava que $31,67 \%$ dos garimpeiros ativos no país tinham naturalidade maranhense, totalizando 92.358 indivíduos. Para que se tenha idéia da importância e da disparidade desse número, em relação às demais naturalidades, considere-se que, no mesmo levantamento, as naturalidades mais freqüentes não chegavam a $7 \%$ do total de 291.727 garimpeiros brasileiros ativos $6,99 \%$ baianos; $6,53 \%$ mineiros; $6,28 \%$ cearenses; $6,25 \%$ paraenses Departamento Nacional de Produção Mineral, 1993).

A grande alta do preço do ouro no mercado internacional, no final dos anos 1970 (cujo pico ocorreu em 1980), induziu o surgimento de um grande surto garimpeiro em vários estados da Amazônia, notadamente no Pará, Mato Grosso, Amazonas, Rondônia, Roraima e Amapá, acarretando também grande aumento na incidência da malária.

Em meados da década de 1980, com a progressiva queda da cotação internacional do ouro, os garimpeiros mobilizados nos anos anteriores começaram a retornar a seus estados de origem, entre os quais se destacava o Maranhão que, assim, em 1987, apresentou a maior casuística de malária registrada, até então, em toda a sua história: 56.627 casos notificados ${ }^{10}$ (a imensa maioria dos quais importados: em alguns municípios, mais de $95 \%$ dos casos), perfazendo um coeficiente de incidência de 1.180,9 casos/10o.ooo habitantes.

A clara correlação entre os principais focos de malária e o retorno de garimpeiros a suas localidades de origem levou a Diretoria Regional do Maranhão da Superintendência de Campanhas de Saúde Pública (Sucam) a proceder ao levantamento sistemático dos garimpos de procedência desses casos, que perdurou até 1993.

A intensificação da busca ativa e do tratamento dos doentes e o combate aos vetores, sobretudo a partir de 1989, com a vigência e os investimentos do Programa de Controle da Malária na Bacia Amazônica, com recursos do Banco Mundial (Silveira e Rezende, 2001), diminuíram a incidência de malária progressivamente até 1993 (39.233 casos em 1988; 37.725 em
1989; 34.955 em 1990; 18.781 em 1991; 18.399 em 1992; 16.222 em 1993).

Em 1992, no entanto, a IX Conferência Nacional de Saúde determinou a descentralização e a incorporação das ações de controle de endemias, então sob responsabilidade da Funasa, pelos serviços de saúde estaduais e municipais, conforme os princípios do Sistema Único de Saúde (SUS), definidos na Constituição de 1988, em um processo gradual que se iniciaria pelos estados do Sudeste e Sul, para finalmente envolver os do Nordeste e Norte.

Ao contrário do previsto na IX Conferência Nacional de Saúde, contudo, esse processo de descentralização deu-se, no Maranhão, em ritmo acelerado. Em 2/10/1994, o jornal O Imparcial publicava (p.4) uma entrevista com o Sr. Márcio Antonio de Almeida, Coordenador Regional da Funasa no Maranhão, intitulada "Maranhão é líder do processo de descentralização executado pela Funasa”. Nessa entrevista, o Sr. Almeida comprovava a afirmação da manchete citando o número de 33 municípios maranhenses já com serviços e atribuições da Funasa descentralizados.

A Coordenação Regional do Maranhão, da Funasa, para efeitos de suas ações de controle de endemias, subdividia-se, na época, em 8 Distritos Sanitários (DS) ${ }^{11}$, e dispunha de uma rede de 7 Unidades Mistas ${ }^{12}$, às quais estavam referenciadas unidades de saúde de menor complexidade ("Centros de Saúde" e "Postos Avançados”, respectivamente). Seguiu-se o rápido fechamento de UMs repassadas pela Funasa aos municípios, sob alegação de falta de recursos para sua manutenção; progressiva diminuição do número de efetivos da instituição (com a suspensão de novas contratações); sucessivas interrupções das ações de combate aos vetores; freqüentes interrupções na distribuição de medicamentos básicos; falta de reciclagem de seus profissionais de campo; somados à falta de vontade política e ao despreparo generalizado dos governos estadual e municipais para assumir as tarefas de controle de endemias - que resultaram em um progressivo recrudescimento dessas endemias, mais especialmente a malária.

\footnotetext{
10 Os dados de incidência de malária citados neste artigo são os oficiais, sucessivamente disponibilizados pela Sucam, pela Funasa e pela Secretaria de Vigilância em Saúde do Ministério da Saúde.

11 DS Pindaré-Mirim, DS Codó, DS São João dos Patos, DS Imperatriz, DS Chapadinha, DS Pedreiras, DS Pinheiro e DS São José de Ribamar.

12 UM Estreito, UM Carolina, UM São Pedro de Água Branca, UM Açailândia, UM Zé Doca, UM Codó e UM Rosário.
} 
Em 1994, a incidência de malária no Maranhão tornava a aumentar, chegando a 28.588 casos, passando para 32.819 casos em 1995; 20.125 em 1996; 20.981 em 1997.

A partir de 1997, a Funasa passou a firmar convênios com os municípios para seu controle, em ritmo acelerado e sem critérios consistentes para avaliar sua capacidade operacional, técnica, administrativa e política para assumir e manter as ações necessárias.

O empenho das Prefeituras, nesse processo, não se deu na escala, no ritmo, com a qualidade técnica e a seriedade de compromisso que a situação exigia (Silveira e Rezende, 2001; Varga, 2002), e o aumento da incidência de malária, no Maranhão, sobretudo na Pré-Amazônia, desenvolveu-se de maneira muito acelerada a partir de 1998, quando se registraram 29.269 casos, passando a 54.798 casos em 1999.

Era notório o despreparo, quando não o desinteresse, de várias Prefeituras da Pré-Amazônia (e do estado, como um todo) no que se referia às políticas de saúde e, mais especificamente, no controle de uma endemia eminentemente rural, e de responsabilidade tradicionalmente federal. Nos contatos que realizamos, nesse período, com Secretários de Saúde dos municípios da região, nos chamou atenção a forte tendência a que sua compreensão do problema e sua política de trabalho, mesmo nos municípios de população predominantemente "rural" (tanto pelos critérios do IBGE, como pelos da Funasa) limitassem-se a manter os serviços e ações mais visíveis do perímetro urbano, quando não mantê-los no limite máximo do sucateamento, impedindo apenas seu fechamento definitivo. A resposta, por exemplo, à pergunta "e como está a situação de saúde de seu município, Sr. Secretário?”, feita no início de 1998, ao Secretário Municipal Saúde de Buriticupu, um dos municípios de população predominantemente rural e com grande incidência de malária, era: "agora vai bem: mês passado comprei remédios para o hospital.” (Varga, 2002, p.230).

O Ministério da Saúde, diante do grande aumento da incidência da malária em toda a Amazônia, realizava os primeiros movimentos para a articulação do Plano de Intensificação das Ações de Controle da Malária na Amazônia Legal (PIACM). Dando continuidade e respaldo formal a essa política de descentralização do controle de endemias, em dezembro de 1999, a Portaria no 1.399, do Ministério da Saúde, estabele- cia que essa atividade passaria a ser de responsabilidade de estados e municípios.

No Maranhão, as primeiras reuniões visando à implementação do PIACM realizaram-se em julho de 200o. Em função da desarticulação e da desmobilização do setor saúde no Governo do Estado, conseqüência de suas recentes reformas administrativas, e em função do já tradicional desinteresse e despreparo das prefeituras diante do problema, o ano de 2000 se encerrou, no Maranhão, com o assombroso número de 78.817 casos de malária registrados (o maior, em toda a história do registro desta endemia no estado) - mesmo sem a ocorrência de surtos garimpeiros significativos.

As ações implementadas, a partir de então, resultaram em uma importante queda da incidência da endemia: 39.507 casos em 2001; 16.000 casos em 2002; 11.434 casos em 2003. Em 2004 verificou-se novo aumento desta incidência (com o registro 14.465 casos), que em 2005 retornou a patamar próximo ao de 2003 (11.191 casos).

\section{Conclusões, Desafios, Perspectivas}

Esta rápida apreciação da trajetória das políticas públicas de saúde no Brasil parece-nos suficiente para afirmar que, nos poucos momentos e espaços em que a população rural foi objeto de estratégias e ações específicas, ela o foi de modo secundário, no bojo de medidas, quase sempre concebidas e desencadeadas pelo Governo Federal, para viabilizar frentes de expansão ou dar retaguarda a estratégias militares de repressão a movimentos guerrilheiros.

Forjados, entretanto, em meios técnicos e acadêmicos, e em movimentos sociais predominantemente urbanos, a legislação sobre o SUS (os dispositivos constitucionais, as leis $n^{0} 8080$ e $n^{0} 8142 / 90$, e as Normas Operacionais), e mesmo os indicadores de saúde disponíveis, não se adequam à expressão das necessidades e situações específicas vivenciadas por comunidades rurais, quanto menos para serem por elas apropriados como instrumentos, no processo de sua organização e mobilização por melhores condições de vida.

Os indicadores de saúde disponíveis e mais freqüentemente utilizados estão desagregados por municípios, e permitem traçar, em grandes linhas, o perfil epidemiológico da população, características gerais 
das redes de serviços públicos e de saúde; porém não permitem identificar as grandes diferenças entre os perfis epidemiológicos e as necessidades de habitantes do perímetro urbano, das de comunidades rurais, indígenas e quilombolas do mesmo município, por exemplo.

Enquanto essa legislação supõe a socialização de condições básicas para o exercício da cidadania - a idéia de que todos os usuários do SUS tenham condições de ao menos chegar às "portas de entrada" do sistema, e de participar e se fazer representar em suas instâncias de controle social (os Conselhos e Conferências de Saúde) - entre as distorções e dificuldades mais freqüentemente enfrentadas pelos Conselhos Municipais de Saúde do Maranhão estão a ingerência dos gestores na definição de sua representação de usuários e o controle daqueles sobre a agenda e dinâmica das reuniões: sobretudo em municípios de população predominantemente rural, suas reuniões ficam condicionadas à liberação dos recursos (e, portanto, salvo na vigência de alternativas, à vontade política de Secretários de Saúde e Prefeitos) para transporte dos conselheiros de comunidades mais distantes e de difícil acesso (Sousa, 1996; Varga, 2002).

A discussão apresentada reforça, a nosso ver, a importância da incidência da malária (Varga, 2003) e da presença de ações e de serviços para seu controle, bem como de proporção e freqüência de representantes de comunidades rurais nas reuniões dos Conselhos Municipais de Saúde, e da autonomia operacional destes, como alguns dos indicadores mais específicos para avaliar o impacto das políticas públicas sobre a saúde de trabalhadores e trabalhadoras rurais nos estados amazônicos (como o Maranhão).

Em 2002, iniciou-se um período de alta contínua (que perdura ainda hoje) das cotações do ouro no mercado internacional, induzindo o início de novo surto garimpeiro na Amazônia. A experiência do surto garimpeiro de 1980 coloca de imediato, portanto, às Secretarias de Saúde de estados e municípios envolvidos e, sobretudo, ao Ministério da Saúde - uma vez que os surtos de garimpagem são de alcance macro- regional, mobilizando grandes contingentes de trabalhadores de vários estados simultaneamente - a tarefa de se apropriar dessas informações para definir uma estratégia mais eficiente de controle, a tempo de organizar-se e mobilizar-se com a agilidade e a rapidez que as frentes de arregimentação destes trabalhadores lhes imprimirão. Além de adequar-se aos já bastante conhecidos determinantes ambientais da presença dos vetores da endemia, as metodologias adotadas para seu controle também devem contemplar as características dos grupos sociais envolvidos em sua cadeia de transmissão, sobretudo garimpeiros e profissionais do sexo, e envolvê-los pró-ativamente no processo (Varga, 2002).

Para que não se verifiquem surtos das dimensões e com os impactos dos da década de 1980, é preciso ir muito além, no entanto, das ações realizadas após a volta dos garimpeiros a seus estados de origem, findas as maiores "fofocas" go dos processos de mobilização desses trabalhadores, e em seus vários garimpos de destino.

\section{Referências}

BASTOS, N. C. B. SESP-FSESP: 1942 - evolução histórica - 1991. Brasília, DF: Fundação Nacional de Saúde, 1996.

BUCHALLA, C. M.; WALDMAN, E. A.; LAURENTI, R. A mortalidade por doenças infecciosas no início e no final do século XX no município de São Paulo.

Revista Brasileira de Epidemiologia, São Paulo, v. 6, n. 4, 2003. Disponível em: <http://www.scielo.br/ scielo.php?script=sci_arttext\&pid=S1415790X2003000400oo8\&lng=pt\&nrm=isso>. Acesso em: 3 jan. 2007.

CAMARGO, E. P. Malária, maleita, paludismo. Ciência e Cultura, São Paulo, v. 55, n. 1, p. 26-29, jan./ mar. 2003.

DEPARTAMENTO NACIONAL DE PRODUÇÃO

MINERAL. Levantamento nacional dos garimpeiros. Brasília, DF, 1993.

13 Jazidas recém-descobertas, no jargão dos garimpos. 
DIAS, J. C. P. Problemas e possibilidades de participação comunitária no controle das grandes endemias no Brasil. Cadernos de Saúde Pública, Rio de Janeiro, v. 14, 1998. Disponível em: <http:// www.scielo.br/scielo.php?script=sci_arttext\&pid =So102-311X1998000600003\&lng=pt\&nrm=iso>.

Acesso em: 4 jan. 2007.

DIAS, R. S. A luta em defesa da saúde no Brasil: do início da institucionalização ao SUS. 1999.

Dissertação (Mestrado em Políticas Públicas) -

Centro de Ciências Sociais, Universidade Federal do Maranhão, São Luís, 1999.

FLEXNER, A. Medical education in the United States and Canada: a report to The Carnegie Foundation for the Advancement of Teaching. New York: The Carnegie Foundation for the Advancement of Teaching, 1972. Disponível em: <http://www.carnegie foundation.org/publications/pub.asp?key=43\& subkey=977>. Acesso em: 31 jun. 2006.

GERSCHMAN, S. A democracia inconclusa. Rio de Janeiro: Fundação Oswaldo Cruz, 1995.

HARDMAN, F. F. Trem fantasma: a modernidade na selva. São Paulo: Companhia das Letras, 1988.

HOCHMAN, G. A era do saneamento. São Paulo: Hucitec: ANPOCS, 1998.

INSTITUTO BRASILEIRO DE GEOGRAFIA E ESTATÍSTICA. Tabela 20o: população residente por sexo, situação e grupos de idade. Disponível em: <http://www.sidra.ibge.gov.br/bda/tabela/listabl. asp? $\mathrm{z}=\mathrm{Cd} \& 0=7 \& \mathrm{i}=\mathrm{P} \& \mathrm{C}=200>$. Acesso em 2 jan. 2007.

MENDES, E. V. (Org.). Distrito sanitário: o processo social de mudança das práticas sanitárias do Sistema Único de Saúde. 4. ed. São Paulo: Hucitec; Rio de Janeiro: Abrasco, 1999.

MERHY, E. E. O capitalismo e a saúde pública. Campinas: Papirus, 1987.

MORAES, H. F. SUCAM: sua origem, sua história. Brasília, DF: Fundação Nacional de Saúde, 1990.

NOVAES, H. M. Contribuição ao estudo de ações integradas em serviços de saúde: análise conceitual e apreciação em programas selecionados na América
Latina. 1989. Tese (Livre-Docência em Saúde Pública) - Faculdade de Saúde Pública, Universidade de São Paulo, São Paulo, 1989.

SANTOS, L. A. C. O pensamento sanitarista na Primeira República: uma ideologia de construção da nacionalidade. Dados: Revista de Ciências Sociais, Rio de Janeiro, v. 28, n. 2, p. 193-210, 1985.

\section{SECRETARIA DE ESTADO DA SAÚDE DE SÃO}

PAULO. Instituto de Saúde. Serviço de Educação em Saúde Pública. A educação e a relação entre os profissionais de saúde e a população. São Paulo: Instituto de Saúde, 1986. Projeto de pesquisa.

SEVCENCKO, N. A revolta da vacina: mentes insanas em corpos rebeldes. São Paulo: Scipione, 1993.

SEVCENCKO, N. Literatura como missão: tensões sociais e criação cultural na Primeira República. São Paulo: Companhia das Letras, 2003.

SILVA, A. R. Malária: estudo clínico e epidemiológico na recente colonização agrícola de Buriticupu, estado do Maranhão. 1975. Dissertação (Mestrado em Medicina/Doenças Infecciosas e Parasitárias) Faculdade Nacional de Medicina, Universidade Federal do Rio de Janeiro, Rio de Janeiro, 1975.

SILVA, A. R.; VARGA, I. V. D.; ALECRIM, W. D. Assistência e prevenção das doenças infecciosas e parasitárias pelo Sistema Único de Saúde. In: COURA, J. R. Dinâmica das doenças infecciosas e parasitárias. Rio de Janeiro: Guanabara Koogan, 2005. v. 1, p. 533-543.

SILVA, L. J. O controle das endemias no Brasil e sua história. Ciência e Cultura, São Paulo, v. 55, n. 1, p. 44-47, jan./mar. 2003.

SILVEIRA, A. C.; REZENDE, D. F. Avaliação da estratégia global de controle integrado da malária no Brasil. Brasília, DF: Organização Pan-Americana de Saúde, 2001.

SOUSA, S. M. P. S. A reforma sanitária no Maranhão: mudança e conservação no processo de organização e de gerenciamento dos serviços de saúde. 1996. Dissertação (Mestrado em Políticas Públicas) Centro de Ciências Sociais, Universidade Federal do Maranhão, São Luís, 1996. 
VARGA, I. V. D. Educação em saúde: ideologias, racionalidades, discursos e práticas institucionais em 15 anos de indigenismo (Brasil, anos 1980-1995). In: ASSIS, E. (Org.). Educação indígena na Amazônia: experiências e perspectivas. Belém: Associação de Universidades Amazônicas: Universidade Federal do Pará, 1996. p. 229-269.

VARGA, I. V. D. Pelas fronteiras e trincheiras do indigenismo e do sanitarismo: a atenção às DST em comunidades indígenas, no contexto das políticas e práticas indigenistas e de saúde, na Pré-Amazônia. 2002. Tese (Doutorado em Saúde Pública) Faculdade de Saúde Pública, Universidade de São Paulo, São Paulo, 2002.
VARGA, I. V. D. Qualidade de vida na pauta dos movimentos de trabalhadores e trabalhadoras rurais no Maranhão. São Luís: Federação dos Trabalhadores e Trabalhadoras na Agricultura do Estado do Maranhão, 2003.

VASCONCELLOS, M. P. C. Os (des)caminhos da formação sanitária e os direitos sociais: uma reflexão a partir da Escola de Saúde de Minas Gerais. 20oo. Tese (Doutorado em Saúde Pública) Faculdade de Saúde Pública, Universidade de São Paulo, São Paulo, 2000. 